\title{
An Emergency Blood Allocation Approach Considering Blood Group Compatibility in Disaster Relief Operations
}

\author{
Zu-Jun Ma ${ }^{1,2} \cdot$ Ke-Ming Wang ${ }^{2,3} \cdot$ Ying Dai $^{2}$
}

Published online: 27 December 2018

(C) The Author(s) 2018

\begin{abstract}
Large-scale sudden-onset disasters may cause massive injuries and thus place great pressure on the emergency blood supplies of local blood banks. When blood is in short supply, blood products gathered urgently to a local blood center should be appropriately allocated to blood banks in the affected area. Moreover, ABO/ $R h(\mathrm{D})$ compatibilities among blood groups must be considered during emergency situations. To minimize the total unmet demand of blood products considering the optimal $\mathrm{ABO} / R h(\mathrm{D})$-compatible blood substitution scheme, a mixed integer programming model is developed and solved efficiently by using a greedy heuristic algorithm. Finally, a numerical example derived from the emergency blood supply scenario of the Wenchuan Earthquake is presented to verify the proposed model and algorithm. The results show that considering $\mathrm{ABO} / R h(\mathrm{D})$-compatible blood substitution can remarkably increase the efficiency of emergency blood allocation while lowering blood shortage, and the preference order of possible $\mathrm{ABO} / R h(\mathrm{D})$-compatible substitutions has an influence on the allocation solution.
\end{abstract}

Ke-Ming Wang

kmwang@swjtu.edu.cn

Ying Dai

ydai@swjtu.edu.cn

1 School of Management, Yangtze University, Jinzhou 434023, China

2 Institute for Logistics and Emergency Management, School of Economics and Management, Southwest Jiaotong University, Chengdu 610031, China

3 School of Information Science and Technology, Southwest Jiaotong University, Chengdu 610031, China
Keywords Blood group compatibility · Blood substitution - Disaster relief - Emergency blood allocation · Greedy heuristic algorithm

\section{Introduction}

Blood transfusion plays a critical role in the provision of medical care for some large-scale sudden-onset disasters due to human-made and natural hazards (Hess and Thomas 2003; Mujeeb and Jaffery 2007; Abolghasemi et al. 2008; Liu et al. 2010; Ibrion et al. 2015). Overburdened with the influx of injured people, a blood center in the affected area will call for urgent collection and transshipment of blood units from some nearby blood centers, and a considerable number of blood products for emergency surgery are usually gathered at the affected blood center. Subsequently, an appropriate blood allocation is required to replenish the blood inventory of each blood bank that is within the service area of the blood center, which is essential for emergency medical services in disaster relief operations. For example, the 2003 Bam Earthquake resulted in 108,985 donated blood units and 21,347 units were actually distributed (Abolghasemi et al. 2008). After the 2008 Wenchuan Earthquake, a total of 107,911 units of blood products were gathered and ultimately 70,415 units were distributed (Ma et al. 2015). Therefore, exploring emergency blood allocation approach to alleviate blood shortage after a large-scale sudden-onset disaster has great practical significance.

Emergency blood allocation is different from the allocation of general relief materials because blood has some remarkable features, such as limited shelf life, multiple kinds of blood products (for example, red blood cells (RBCs), plasma, and platelets), and multiple blood groups 
with complex $\mathrm{ABO} / R h(\mathrm{D})$ compatibility. In the existing literature on blood allocation, each kind of blood product is regarded as a single material and thus the problem is degenerated into a transportation problem (Gregor et al. 1982; Hemmelmayr et al. 2009; Ganesh et al. 2014). There are eight blood groups for each kind of blood product. Moreover, $\mathrm{ABO} / R h(\mathrm{D})$-compatible blood substitution is allowed in cases of blood shortage during emergencies, that is, each kind of blood product with a specific group not only can satisfy its own demand, but also can be used as a substitute for the same product with other compatible groups. $\mathrm{ABO} / R h(\mathrm{D})$-compatible blood substitution is a recourse action that offers incredible alternatives to meet demand when supply of a specific blood is restricted in emergencies (NHS 2012). There are specific and complicated substitution rules for different blood products. Figure 1 shows all possible compatible substitutions among eight $\mathrm{ABO} / R h(\mathrm{D})$ blood groups for red blood cell (that is, each blood group can only be substituted by the blood group whose arrow points directly or indirectly at it). For example, blood group $\mathrm{AB}+$ can be substituted by all other seven blood groups, and $\mathrm{O}-$ can substitute all other blood groups (Lang 2010; Duan and Liao 2014). As shown in Table 1, blood demand should first be satisfied by the exact $\mathrm{ABO} / R h(\mathrm{D})$ match so that preference order " 1 " stands for the highest priority, preference order " 2 " stands for the possible compatible substitutions for red blood cells, and " $\infty$ " means not feasible.

$\mathrm{ABO} / R h(\mathrm{D})$-compatible blood substitution further complicates the emergency blood allocation problem in disaster relief operations. In recent years, some researchers such as Zahiri and Pishvaee (2017) and Osorio et al. (2018) have considered the compatible substitution for the problems of blood supply chain design and blood fractionation. However, the blood allocation problem with $\mathrm{ABO} /$ $R h(\mathrm{D})$ compatibility has not been well investigated yet. First, allocation should try to control the ratio of allotypic

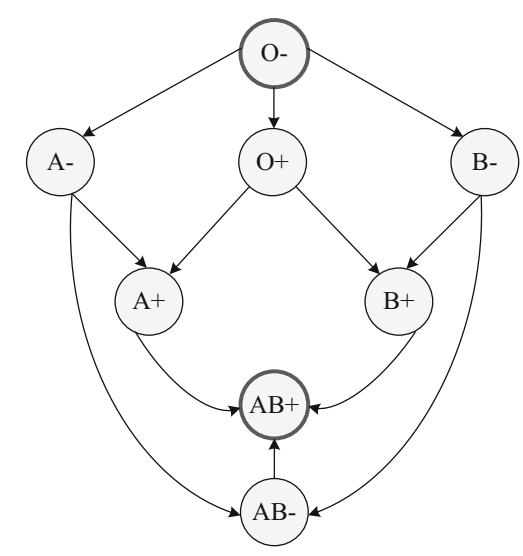

Fig. $1 \mathrm{ABO} / R h(\mathrm{D})$-compatible blood substitution graph of red blood cell $(\mathrm{RBC})$
Table 1 Possible ABO/Rh(D)-compatible substitutions for red blood cell (RBC)

\begin{tabular}{|c|c|c|c|c|c|c|c|c|}
\hline \multirow[t]{2}{*}{ Donor } & \multicolumn{8}{|c|}{ Patient } \\
\hline & $\mathrm{AB}+$ & $\mathrm{AB}-$ & B+ & B- & $\mathrm{A}+$ & A- & $\mathrm{O}+$ & $\mathrm{O}-$ \\
\hline $\mathrm{AB}+$ & 1 & $\infty$ & $\infty$ & $\infty$ & $\infty$ & $\infty$ & $\infty$ & $\infty$ \\
\hline $\mathrm{AB}-$ & 2 & 1 & $\infty$ & $\infty$ & $\infty$ & $\infty$ & $\infty$ & $\infty$ \\
\hline $\mathrm{B}+$ & 2 & $\infty$ & 1 & $\infty$ & $\infty$ & $\infty$ & $\infty$ & $\infty$ \\
\hline B- & 2 & 2 & 2 & 1 & $\infty$ & $\infty$ & $\infty$ & $\infty$ \\
\hline $\mathrm{A}+$ & 2 & $\infty$ & $\infty$ & $\infty$ & 1 & $\infty$ & $\infty$ & $\infty$ \\
\hline A- & 2 & 2 & $\infty$ & $\infty$ & 2 & 1 & $\infty$ & $\infty$ \\
\hline $\mathrm{O}+$ & 2 & $\infty$ & 2 & $\infty$ & 2 & $\infty$ & 1 & $\infty$ \\
\hline $\mathrm{O}-$ & 2 & 2 & 2 & 2 & 2 & 2 & 2 & 1 \\
\hline
\end{tabular}

transfusion and adopt homotype transfusion as much as possible (BSMS 2003). Thus, decision makers are faced with the dilemma of creating a solution with less shortage and less substitution in the allocation solution.

Moreover, the substitution rules are not identical among different blood products. The preference order of possible $\mathrm{ABO} / R h(\mathrm{D})$-compatible substitutions are also not same, but currently there is no research report clarifying it. Although one blood group can be substituted by other blood groups, doctors will choose a suitable blood group for substitution transfusion according to their clinical experience.

Therefore, this study aimed to develop a decisionmaking framework for the multi-product, multi-group emergency blood allocation problem in disaster relief operations. Furthermore, we evaluate the influence of an $\mathrm{ABO} / R h(\mathrm{D})$-compatible substitution policy for emergency blood allocation decision making. The primary contributions of this study include:

- Propose a mixed integer programming model for the multi-product multi-group emergency blood allocation problem in disaster relief operations, which considers the complex $\mathrm{ABO} / R h(\mathrm{D})$ compatibilities among blood groups.

- Consider the substitution rate as well as substitution preference order, which enhances the practicality of the developed model.

- Propose a greedy heuristic algorithm to determine the near-optimal scheme of the emergency blood allocation problem in disaster relief operations.

- Quantify the effect of an $\mathrm{ABO} / R h(\mathrm{D})$-compatible substitution policy on emergency blood allocation in disaster relief operations under different substitution relations and preference orders of different blood products. 
The remainder of this article is organized as follows. In Sect. 2, the related literature is reviewed. In Sect. 3, a multi-product multi-group emergency blood allocation model for disaster relief operations is developed based on a mixed integer programming method. In Sect. 4, a greedy heuristic algorithm is proposed to solve the model. In Sect. 5, a numerical example is presented to verify the proposed model and algorithm. Finally, the results are concluded in Sect. 6, and research implications and managerial insights are also discussed.

\section{Literature Review}

Operations management in blood supply chain has attracted much attention focusing mainly on blood inventory management of hospital blood banks or regional blood centers (Nahmias 1982; Prastacos 1984; Pierskalla 2005; Karaesmen et al. 2011; Bakker et al. 2012; Beliën and Forcé 2012; Osorio et al. 2015). However, the blood allocation problem has not been well investigated quantitatively by scholars. Prastacos (1981) proposed an optimal allocation policy to minimize both expected average shortages and expected average expirations in a region where a perishable product (for example, blood) is periodically produced and allocated among several locations. Sapountzis (1984) developed an integer programming model to allocate blood from a regional blood transfusion service center to local hospitals according to the characteristics of the blood. Federgruen et al. (1986) presented an allocation model for distributing a perishable product (for example, blood) from a regional center to a given set of locations with random demands. They considered the combined problem of allocating the available inventory at the center while deciding how these deliveries should be performed. Atkinson et al. (2012) studied the issue of whether transfusing fresher blood can be achieved without jeopardizing blood availability and proposed a novel allocation strategy for blood transfusions, which focuses on the tradeoff between the age and availability of transfused blood. Olusanya and Adewumi (2014) presented the use of meta-heuristic techniques to optimize the blood assignment problem in a blood bank to minimize the total amount of blood resources imported from outside. All the above studies aimed at solving the blood allocation problem under the routine conditions and did not consider the effect of $\mathrm{ABO} / R h(\mathrm{D})$-compatible substitution.

Currently there is a growing research interest in the emergency blood supply problem, such as post-disaster location analysis of regional blood centers (Sahin et al. 2007; Sharma et al. 2017), robust design of emergency blood supply networks (Jabbarzadeh et al. 2014), supply chain design for blood supply in disasters (Ensafian and
Yaghoubi 2017; Fahimnia et al. 2017; Fazli-Khalaf et al. 2017; Khalilpourazari and Khamseh 2017; Samani et al. 2018), and an age-based policy for blood transshipment during blood shortage (Wang and Ma 2015). But the emergency blood allocation problem in disaster relief operations has never been discussed.

Specifically, one important feature of blood is possible $\mathrm{ABO} / R h(\mathrm{D})$-compatible substitutions among the eight blood groups-if the exact $\mathrm{ABO} / R h(\mathrm{D})$ match is unavailable, an $\mathrm{ABO} / R h(\mathrm{D})$-compatible match can be sought by following $\mathrm{ABO} / R h(\mathrm{D})$ compatibility (Lang 2010; Duan and Liao 2014). ABO/Rh(D)-compatible blood substitution is an important way to ensure an adequate blood supply, especially when blood is in shortage or under emergency conditions. $\mathrm{ABO} / R h(\mathrm{D})$-compatible blood substitution has only been considered in recent years, and we list the literature in Table 2 .

In the studies listed in Table 2, blood substitution has only been considered in a routine blood collection and supply problem, where most objectives are based on cost, and the effects of substitution rate constraint are ignored. Emergency blood allocation problem is quite different from the studies in Table 2-it should consider the constraint of substitution rate. Our objective was to lessen both shortage and substitution in an allocation solution. Moreover, the problem also has scenarios under preference order of possible substitutions.

In the above literature, emergency blood allocation problem considering $\mathrm{ABO} / R h(\mathrm{D})$-compatible substitution has not been studied yet. To fill this gap and cater to the practical demand in disaster relief operations, this study developed a mixed integer programming model for emergency blood allocation considering $\mathrm{ABO} / R h(\mathrm{D})$ compatibilities among blood groups, and a heuristic algorithm was proposed to explore the performance of an emergency blood allocation policy with $\mathrm{ABO} / R h(\mathrm{D})$-compatible substitution.

\section{Model Framework}

This section describes the emergency blood allocation problem in disaster relief operations and its mathematical formulation.

\subsection{Problem Description}

This study considered the emergency blood allocation problem after a large-scale disaster. Figure 2 illustrates emergency blood collection and transshipment from some nearby blood centers after a disaster has caused heavy casualties and a batch of blood products has been gathered at the regional blood center in the affected area. In this kind 
Table 2 Recent studies on blood substitution

\begin{tabular}{|c|c|c|c|c|c|c|}
\hline Authors & Research problem & $\begin{array}{l}\text { Blood } \\
\text { products }\end{array}$ & Objectives & $\begin{array}{l}\text { Different substitution } \\
\text { rules for different } \\
\text { products }\end{array}$ & $\begin{array}{l}\text { Substitution } \\
\text { priority }\end{array}$ & $\begin{array}{l}\text { Substitution } \\
\text { rate }\end{array}$ \\
\hline Lang (2010) & $\begin{array}{l}\text { Inventory } \\
\text { management }\end{array}$ & RBCs & $\begin{array}{l}\text { Shortages and the number of } \\
\text { transshipments }\end{array}$ & - & Yes & No \\
\hline $\begin{array}{l}\text { Abdulwahab } \\
\text { and Wahab } \\
\text { (2014) }\end{array}$ & $\begin{array}{l}\text { Inventory } \\
\text { management }\end{array}$ & Platelet & $\begin{array}{l}\text { Shortage, outdating, } \\
\text { inventory level, and } \\
\text { reward gained }\end{array}$ & - & No & No \\
\hline $\begin{array}{l}\text { Duan and Liao } \\
\text { (2014) }\end{array}$ & $\begin{array}{l}\text { Inventory } \\
\text { management }\end{array}$ & $\mathrm{RBCs}$ & Outdate rate & - & No & No \\
\hline $\begin{array}{l}\text { Ensafian et al. } \\
\text { (2017) }\end{array}$ & $\begin{array}{l}\text { Supply chain, } \\
\text { donor prediction }\end{array}$ & Platelet & Cost & - & Yes & No \\
\hline $\begin{array}{l}\text { Zahiri and } \\
\text { Pishvaee } \\
\text { (2017) }\end{array}$ & $\begin{array}{l}\text { Supply chain } \\
\text { design }\end{array}$ & $\begin{array}{l}\text { RBCs, } \\
\text { plasma }\end{array}$ & Cost, unsatisfied demand & Yes & No & No \\
\hline $\begin{array}{l}\text { Dillon et al. } \\
\text { (2017) }\end{array}$ & $\begin{array}{l}\text { Supply chain, } \\
\text { inventory } \\
\text { management }\end{array}$ & RBCs & Cost & - & Yes & No \\
\hline $\begin{array}{l}\text { Najafi et al. } \\
\text { (2017) }\end{array}$ & $\begin{array}{l}\text { Inventory } \\
\text { management }\end{array}$ & Blood & Shortage, cost & No & Yes & No \\
\hline $\begin{array}{l}\text { Jafarkhan and } \\
\text { Yaghoubi } \\
\text { (2018) }\end{array}$ & $\begin{array}{l}\text { Inventory routing } \\
\text { problem }\end{array}$ & $\mathrm{RBCs}$ & Cost & - & No & No \\
\hline $\begin{array}{l}\text { Osorio et al. } \\
\text { (2018) }\end{array}$ & Blood fractionation & $\begin{array}{l}\text { RBCs, } \\
\text { plasma, } \\
\text { platelets }\end{array}$ & Cost, number of donors & Yes & No & No \\
\hline
\end{tabular}

Fig. 2 Emergency blood allocation problem in disaster relief operations

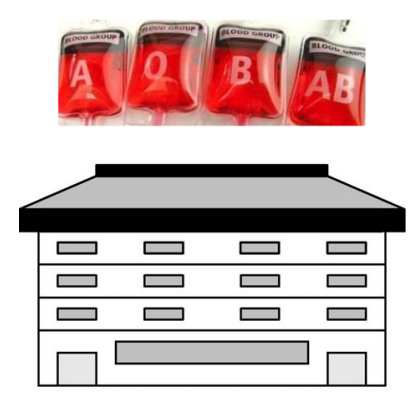

Regional blood center (blood products gathered)

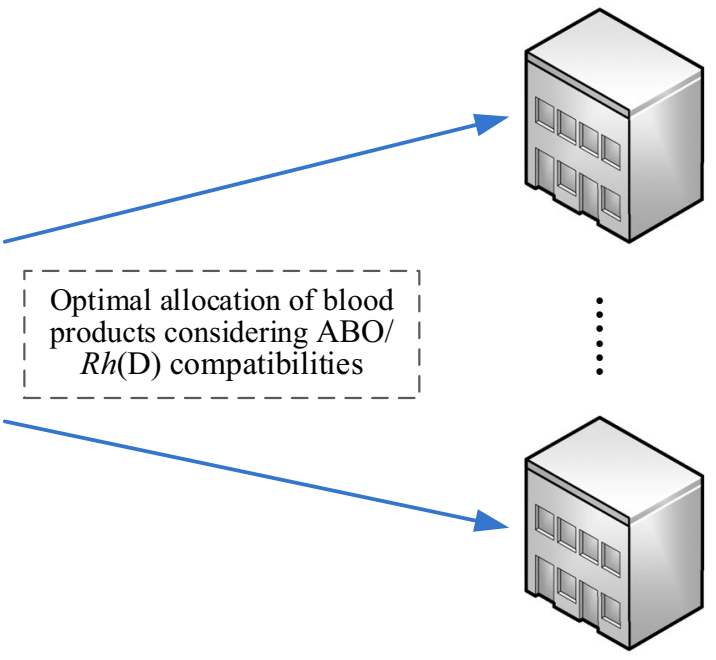

Blood banks in the affected region of emergency situation, the blood products are then in need of timely allocation to the affected blood banks within the service area of the blood center, so as to meet the local demand for blood transfusions in emergency relief.

The volume of blood products is smaller than other emergency relief goods, and the distance between a blood center and its affiliated blood banks is often not very farin general, one car can transport all the allocated blood products from a blood center to a blood bank within a day. So for this kind of urgent allocation problem in post-disaster blood management, our research focused on allocation rather than inventory or transportation decision 
problem. The main aim was to minimize the total unmet demand of blood products of the affected blood banks while optimizing the $\mathrm{ABO} / R h(\mathrm{D})$-compatible substitution scheme. Based on the above prerequisites, the following assumptions were made to rationalize the proposed model.

(1) The total amount of blood products to be allocated at the blood center is sufficient to satisfy the total demand from all blood banks in the affected region. But the supply of blood products with a specific blood group does not always match the total demand for this kind of blood product at all blood banks. The remaining lifetime of these products is assumed longer than the period of blood demand for emergency relief.

(2) According to the equity principle, the shortage or substitution amount of each kind of blood product is apportioned among the blood banks according to their demand proportions.

(3) Since homotype blood transfusion has the best curative effect, the maximum $\mathrm{ABO} / R h(\mathrm{D})$-compatible substitution rate should be set when $\mathrm{ABO} / R h(\mathrm{D})$ compatible blood substitution is inevitable in emergencies. Moreover, to improve the clinical efficiency of emergency blood transfusions, $\mathrm{ABO} / R h(\mathrm{D})$-compatible blood substitutions among different blood groups should follow the principle that the higher the substitution priority, the better.

\subsection{Model Formulation}

The notations used throughout the remainder of this article are as follows.

\subsubsection{Parameter}

$K$ Set of all blood groups, that is, $K=\{\mathrm{A}+, \mathrm{B}+$, $\mathrm{AB}+, \mathrm{O}+, \mathrm{A}-, \mathrm{B}-, \mathrm{AB}-, \mathrm{O}-\}$.

$E \quad$ Set of all arcs of a directed graph $G=\{K, E\}$, and represents $\mathrm{ABO} / R h(\mathrm{D})$-compatible blood substitutions, where $E \subseteq K \times K$. A directed arc $[i, k](i, k \in K)$ denotes that blood group $k$ can be substituted by blood group $i$.

$U_{i} \quad$ Set of blood groups that can be substituted by blood group $i$, that is, $U_{i}=\{k \mid[i, k] \in E\}$ and $U_{i} \subseteq K$.

$V_{i} \quad$ Set of blood groups that can substitute blood group $i$, that is, $V_{i}=\{k \mid[k, i] \in E\}$ and $V_{i} \subseteq K$.

$J \quad$ Set of blood banks in the affected area.

$P \quad$ Set of blood products (such as whole blood, plasma, and RBCs).

$W \quad$ Set of priority weights of $\mathrm{ABO} / R h(\mathrm{D})$-compatible blood substitution. $w_{i k} \quad$ Priority weight of substituting blood group $k$ with blood group $i$. For any blood group $k$, blood group $i$ with a smaller $w_{i k}$ has a higher substitution priority, $\forall w_{i k} \in W, i \in K, k \in U_{i}$.

$s_{k p} \quad$ Available blood product $p$ with blood group $k$ at the local blood center, $\forall k \in K, p \in P$.

$d_{k p, j} \quad$ Demand for blood product $p$ with blood group $k$ at blood bank $j, \forall k \in K, p \in P, j \in J$.

$\delta \quad$ Maximum $\mathrm{ABO} / R h(\mathrm{D})$-compatible substitution rate among different blood groups, that is, the maximum ratio of substitution amount to total demand of each blood product.

$\rho \quad$ Per-unit penalty on the blood shortage.

\subsubsection{Decision variables}

$x_{k p, j} \quad$ Amount of blood product $p$ with blood group $k$ allocated to blood bank $j, \forall k \in K, p \in P, j \in J$.

$y_{i k p, j} \quad$ Amount of blood group $i$ that is used to substitute blood group $k$ for blood product $p$ at blood bank $j$, $\forall i \in K, k \in U_{i}, p \in P, j \in J$.

$z_{k p, j} \quad$ Shortage of blood product $p$ with blood group $k$ at blood bank $j, \forall k \in K, p \in P, j \in J$.

To solve the emergency blood allocation problem considering $\mathrm{ABO} / R h(\mathrm{D})$-compatible substitution, a mixed integer programming model is developed as follows:

$$
\begin{aligned}
\min F= & \rho \sum_{p \in P} \sum_{k \in K} \sum_{j \in J} z_{k p, j} \\
& +\sum_{k \in K} \sum_{i \in V_{k}}\left(w_{i k} \times \sum_{j \in J} \sum_{p \in P} y_{i k p, j}\right)
\end{aligned}
$$

s.t.

$$
\begin{aligned}
& \rho \geq \max \left(w_{i k}\right), \forall i \in V_{k}, k \in K \\
& w_{k k} \leq w_{i k}, \forall i \in V_{k}, k \in K \\
& x_{k p, j}+\sum_{i^{\prime} \in V_{k}} y_{i^{\prime} k p, j}-\sum_{i \in U_{k}} y_{k i p, j}=d_{k p, j}-z_{k p, j}, \\
& \forall k \in K, p \in P, j \in J \\
& \sum_{j \in J} x_{k p, j} \leq s_{k p}, \forall k \in K, p \in P \\
& z_{k p, j} \leq\left[\sum_{j \in J} z_{k p, j} \times\left(d_{k p, j} / \sum_{j \in J} d_{k p, j}\right)\right] \\
& \forall k \in K, p \in P, j \in J \\
& \sum_{i \in U_{k}} y_{k i p, j} \leq x_{k p, j}, \forall k \in K, p \in P, j \in J \\
& \sum_{k \in K} \sum_{i \in V_{k}} y_{i k p, j} \leq \delta \sum_{k \in K} d_{k p, j}, \forall p \in P, j \in J
\end{aligned}
$$


Fig. 3 Flowchart of the greedy heuristic algorithm

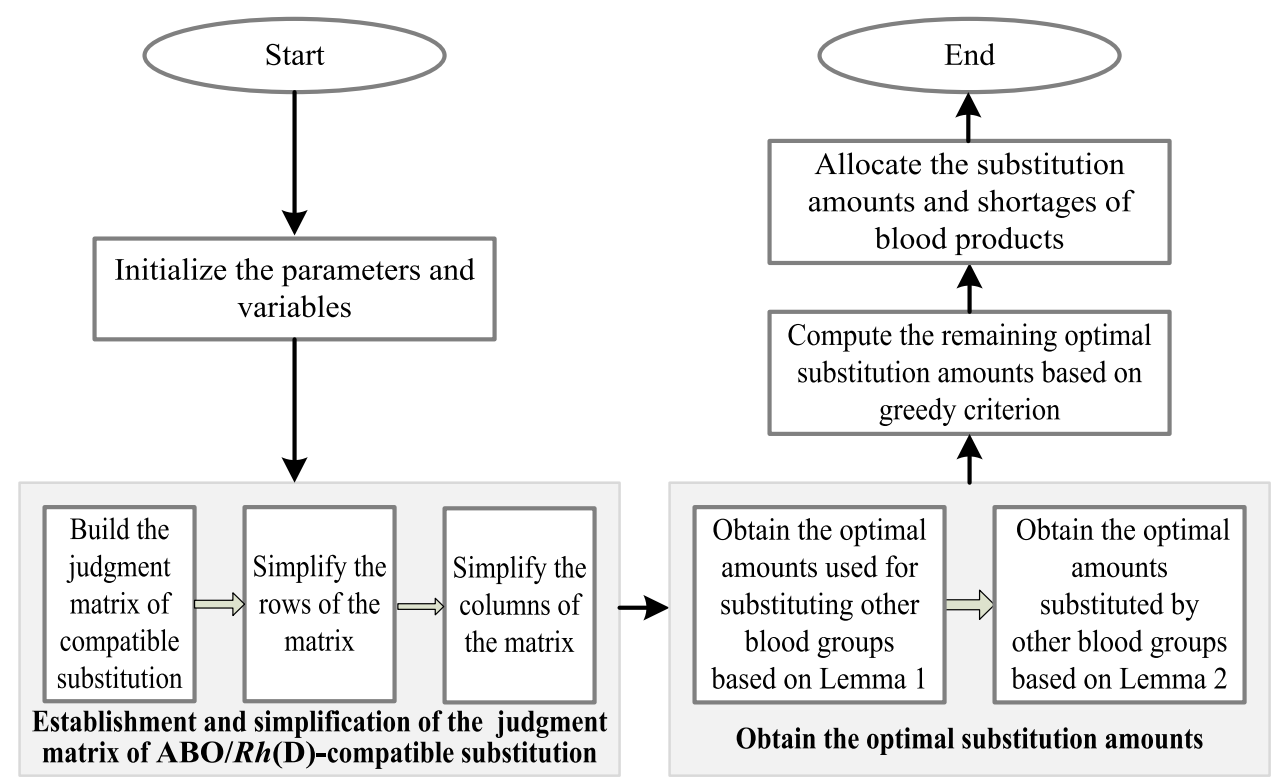

$\begin{aligned} y_{i k p, j} & \leq\left\lceil\sum_{j \in J} y_{i k p, j} \times\left(d_{k p, j} / \sum_{j \in J} d_{k p, j}\right)\right\rceil, \\ \forall k & \in K, i \in V_{k}, p \in P, j \in J\end{aligned}$

$z_{k p, j}, y_{i k p, j}, x_{k p, j} \geq 0$ and all of them are integers, $\forall i$

$\in V_{K}, k \in K, p \in P, j \in J$

There are actually two targets in the problem-the first is to minimize shortage and the second is to get the best substitution solution under the substitution priority order. Initially, we preferred to build a bi-level programming model or a dual objective function model for this problem. But the bi-level programming model and the dual objective function model were also difficult to develop efficient algorithms to solve. Eventually we chose the single objective nonlinear mixed integer programming model to directly solve the two targets under some special constraints.

Constraint 2 ensures that the shortage weight $\rho$ is larger than the largest priority weight of substituting $w_{i k}$ between any blood group $i$ and $k$. Constraint 3 ensures that the homotype allocation is preferred than the allotypic allocation. As lower weight among blood groups stands for higher substitution priority, we can use the min-sum function to express the two targets in one formula with the above two constraints. So the objective function 1 is to minimize the sum of the total priority weight of $\mathrm{ABO} /$ $R h(\mathrm{D})$-compatible blood substitutions and the total shortage of all blood products at all blood banks in the affected area.

Constraint 4 denotes the formula relation among the supply, the demand, and the shortage. The demand of blood product $p$ with blood group $k$ at blood bank $j$ is satisfied by the same group product and substitutions of other blood groups, and the unsatisfied demand will be the shortage. Constraint 5 ensures that the total demand for any type of blood product may not exceed its supply. Constraint 6 denotes that the shortage of each type of blood product is allocated among all blood banks according to their demand proportions. Constraint 7 denotes the limitation on the substitution amount of each blood group at each blood bank. Constraint 8 represents the total substitution amount of each blood product at each blood bank under the limitation of substitution rate. Constraint 9 denotes that the substitution amount of each blood product is allocated among all blood banks according to their demand proportions. Constraint 10 defines the domain of decision variables.

\section{Model Solution}

The proposed model is nonlinear due to constraints 6 and 9 . But there is no existing algorithm for this allocation problem considering the priorities of $\mathrm{ABO} / R h(\mathrm{D})$-compatible substitution. Due to the complexity of $\mathrm{ABO} / R h(\mathrm{D})-$ compatible substitution rules, the above mixed integer programming model is a high-dimensional optimization problem. To solve the model efficiently, in this study we applied a greedy heuristic algorithm in which a judgment matrix that includes $\mathrm{ABO} / R h(\mathrm{D})$-compatible blood substitution relations was used to reduce the computational complexity.

As shown in Fig. 3, a judgment matrix of $\mathrm{ABO} / R h(\mathrm{D})-$ compatible blood substitution was first built to denote the $\mathrm{ABO} / R h(\mathrm{D})$ compatibility for each blood product. Then, 
the judgment matrix was simplified according to the total supply and demand of blood products with each blood group. Next, two lemmas on $\mathrm{ABO} / R h(\mathrm{D})$-compatible substitution were used to obtain the optimal substitution amounts of those blood products with blood groups that satisfy the lemmas. Afterwards, the greedy rule was used to optimize the remaining optimal substitution amounts and obtain the substitution amounts and shortages of blood products with different blood groups. Finally, the shortages and substitutions of blood products were allocated among blood banks.

Before the detailed steps of the greedy heuristic algorithm are presented, we first explore the quantitative properties of $\mathrm{ABO} / R h(\mathrm{D})$-compatible blood substitution. Let $y_{i k p}^{*}$ be the optimal amount of blood product $p$ with blood group $k$ substituted by blood group $i$ in consideration of blood substitution priority, $\forall i \in K, k \in U_{i}, p \in P, j \in J$. Based on Lemmas 1 and 2, we can determine $y_{i k p}^{*}$ among eligible blood groups.

Lemma 1 Assume that the supply of blood product $p$ with blood group $k$ is superfluous, if $\left(\sum_{j} d_{i p, j}-s_{i p}\right)>0$ for $i \in U_{k}$, we can get

$$
\begin{gathered}
y_{k i p}^{*}=\min \left\{s_{k p}-\sum_{j} d_{k p, j}, \sum_{j} d_{i p, j}-s_{i p}\right\} \text {, when } \\
\left|U_{k}\right|==1 \quad \text { and } \quad w_{k i}=\min \left\{w_{k i} \mid w_{k i} \in W\right\} .
\end{gathered}
$$

Lemma 1 implies that for blood product $p$, if the supply of blood group $k$ is superfluous and only group $i$ is in shortage among all those blood groups that can be substituted with blood group $k$, then we can determine the optimal value of $y_{k i p}^{*}$ when $w_{k i}$ equals the minimum priority weight of blood substitution.

Lemma 2 Assume that blood product $p$ with blood group $k$ is inadequate, if $\left(s_{i p}-\sum_{j} d_{i p, j}\right)>0$ for $i \in V_{k}$, we can get $y_{i k p}^{*}=\min \left\{\sum_{j} d_{k p, j}-s_{k p}, s_{i p}-\sum_{j} d_{i p, j}\right\}$ when $\left|V_{k}\right|==1$ and $w_{i k}==\min \left\{w_{i k} \mid w_{i k} \in W\right\}$.

Lemma 2 implicates that for blood product $p$, if the supply of blood group $k$ is inadequate and only group $i$ is in surplus among all those blood groups that can substitute group $k$, then we can determine the optimal value of $y_{i k p}^{*}$ when $w_{i k}$ equals the minimum priority weight of blood substitution. On these bases, the process of the greedy heuristic algorithm is as follows:

(1) Initialization
Step 1: Input the data of blood supply $s_{k p}$ and blood demand $d_{k p, j}$, and set the priority weights of blood substitution $w_{i k}$ and the maximum $\mathrm{ABO} / R h(\mathrm{D})$-compatible substitution rate $\delta$. Initialize the optimal total allocation amount $x_{k p}^{*}$, the optimal total substitution amount $y_{i k p}^{*}$, and the optimal total shortage $z_{k p}^{*}$ as 0 matrices.

Step 2: Obtain the total demand for each blood product with each blood group $D_{k p}=\sum_{j \in J} d_{k p, j}$ and its initial allocation $x a_{k p}=\min \left(s_{k p}, D_{k p}\right)$. Thus, the initial shortage is $z a_{k p}=D_{k p}-x a_{k p}$, or the initial surplus is $s a_{k p}=s_{k p}-x a_{k p}$. Let $x_{k p}^{*}=x a_{k p}$.

(2) Simplifying the judgment matrix of $\mathrm{ABO} / R h(\mathrm{D})$ compatible blood substitution

Step 3: Obtain the judgment matrix of $\mathrm{ABO} / R h(\mathrm{D})$ compatible blood substitution $U V \_n o w$ according to $\mathrm{ABO} / R h(\mathrm{D})$ compatibility as well as the supply and demand of blood products with each blood group.

Step 3.1: Obtain a priority weight matrix of blood substitution $U V$ according to $\mathrm{ABO} / R h(\mathrm{D})$ compatibility. Step 3.2: Initialize $U V \_$now as a $|K| \times|K| \times|P| 0$ matrix, and let $i=1$.

Step 3.3: Let $U V \_n o w_{:,, i}=U V$, where $:,:, i$ denotes all the columns and rows on page $i$ of the judgment matrix, that is, the $i$ th 2-D matrix in $U V \_$now whose size is $|K| \times|K|$, similarly hereinafter. Let $j=2$, and $k=1$.

Step 3.3.1: If the initial surplus $s a_{i j}==0$, then $U V \_$now $_{j, ., i}=0$.

Step 3.3.2: If the initial shortage $z a_{i k}==0$, then $U V \_$now: $, k, i=0$.

Step 3.3.3: Let $j=j+1$ and $k=k+1$; repeat Steps 3.3.1 and 3.3.2 until $j==|K|$ and $k==|K|-1$.

Step 3.4: Let $i=i+1$, repeat Step 3.3 until $i==|P|$.

Figure 4 shows the transformation process of $U V \_$now in Step 3. Let the priority weights of $\mathrm{ABO} / R h(\mathrm{D})$-compatible blood substitution be equal to the values listed in Table 1; thus $\min (W)=2$, and $\max (W)=8$. We can get a priority weight matrix $U V$, as shown in Fig. 4 a, where 0 denotes that there is no need to consider its corresponding row and column in optimizing $\mathrm{ABO} / R h(\mathrm{D})$-compatible blood substitution. $U V_{2,1}=2$ denotes that when a blood product with blood group $\mathrm{AB}+$ is in shortage, the same type of blood product with $\mathrm{AB}-$ has the highest substitution priority. Similarly, $U V_{2,8}=8$ denotes that when a blood product with blood group $\mathrm{AB}+$ is in shortage, the same type of blood product with blood group $\mathrm{O}-$ has the lowest substitution priority. 
Fig. 4 Transformation of the judgment matrix of $\mathrm{ABO} /$ $R h(\mathrm{D})$-compatible blood substitution

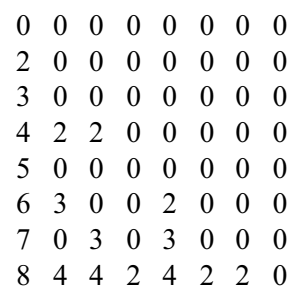

(a) $U V$

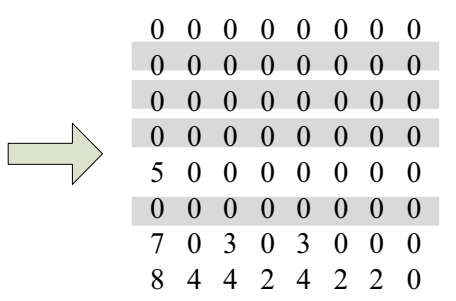

(b) Simplify the row of $U V \_$now

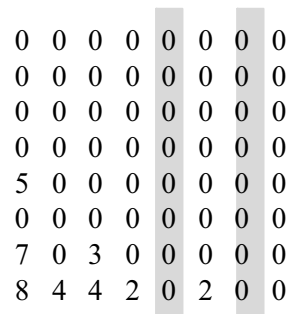

(c) Simplify the column of $U V \_n o w$
For blood product $i$, if the surplus supply of blood group $j$ is equal to zero, that is, $s a_{i j}==0$, then blood group $j$ cannot be used to substitute other blood groups. Thus, all the values of row $j$ in matrix $U V \_n o w_{:,, i}$ should be zero, and it is unnecessary to consider $\mathrm{ABO} / R h(\mathrm{D})$ compatibility between this row and all the columns during the optimization process. The simplification process of rows in matrix $U V \_n o w$, as shown in Fig. 4b, demonstrates the computation process in Step 3.3.1.

Similarly, for blood product $i$, if the surplus supply of group $k$ is equal to zero, that is, $z a_{i k}==0$, then group $k$ is of no need to be substituted by other blood groups. Thus, all the values of column $k$ in matrix $U V \_n o w_{:,, i}$ should be 0 , and it is unnecessary to consider $\mathrm{ABO} / R h(\mathrm{D})$ compatibility between this column and all the rows during the optimization process. The simplification process of columns in matrix $U V \_n o w$, as shown in Fig. 4c, demonstrates the computation process in Step 3.3.2.

In conclusion, the matrix $U V \_$now established in Step 3 not only can denote the substitution priority among different blood groups, but also can denote $\mathrm{ABO} / R h(\mathrm{D})$ compatibility according to the actual supply and demand of blood, which reduces non-zero values in the matrix and then simplifies the subsequent computation process.

(3) Computing the optimal substitution amounts based on $\mathrm{ABO} / R h(\mathrm{D})$ compatibility

Step 4: Obtain the maximum substitution amount of each blood product $y m_{p}$ according to the maximum $\mathrm{ABO} /$ $R h(\mathrm{D})$-compatible substitution rate $\delta$

Step 5: Obtain the optimal substitution amounts of each blood product with each blood group that satisfies Lemmas 1 and 2.

Step 5.1: Let $i=1$.

Step 5.2: Let $j=2$ and use Lemma 1.

Step 5.2.1: If $\operatorname{sum}\left(U V_{-} n o w_{j,, i}\right)==\min \left\{w_{i k} \mid w_{i k} \in W\right\}$, then let the sequence number of the corresponding column in $U V \_n o w$ be $g$ and $y_{j g i}^{*}=\min \left(s a_{i j}, z a_{i g}\right)$; otherwise, go to Step 5.2.4.

Step 5.2.2: If $y_{j g i}^{*}==s a_{i j}$, then $U V \_n o w_{j, ., i}=0$; otherwise, $U V \_$now $, g, i=0$.
Step 5.2.3: Let $s a_{i j}=s a_{i j}-y_{j g i}^{*}, \quad z a_{i g}=z a_{i g}-y_{j g i}^{*}$, $x_{j i}^{*}=x_{j i}^{*}+y_{j g i}^{*}$, and $y m_{i}=y m_{i}-y_{j g i}^{*}$.

Step 5.2.4: Let $j=j+1$ and repeat Steps 5.2.1 to 5.2.3 until $j==|K|$.

Step 5.3: Let $k=1$ and use Lemma 2.

Step 5.3.1: If $\operatorname{sum}\left(U V \_n o w_{:, k, i}\right)==\min \left\{w_{i k} \mid w_{i k} \in W\right\}$, then let the sequence number of the corresponding row in $U V \_n o w$ be $g$ and $y_{g k i}^{*}=\min \left(s a_{i g}, z a_{i k}\right)$; otherwise, go to Step 5.3.4.

Step 5.3.2: If $y_{g k i}^{*}==s a_{i g}$, then $U V \_n o w_{g,, i}=0$; otherwise, $U V \_n o w_{:, k, i}=0$.

Step 5.3.3: Let $s a_{i g}=s a_{i g}-y_{g k i}^{*}, \quad z a_{i k}=z a_{i k}-y_{g k i}^{*}$, $x_{g i}^{*}=x_{g i}^{*}+y_{g k i}^{*}$, and $y m_{i}=y m_{i}-y_{g k i}^{*}$.

Step 5.3.4: Let $k=k+1$ and repeat Steps 5.3.1 to 5.3.3 until $k==|K|-1$.

Step 5.4: Let $i=i+1$ and repeat Steps 5.2 and 5.3 until $i==|P|$.

In Step 5, we not only use Lemmas 1 and 2 to optimize the computation process, but also to further simplify the matrix $U V \_$now for the subsequent computation. For example, in Step 5.2.2, if $y_{j g i}^{*}==s a_{i j}$, there will be no supply of blood product $i$ with blood group $j$ and all the values of column $j$ in the matrix $U V_{-}$now $w_{:,, i}$ should be zero; otherwise, $y_{j g i}^{*}==z a_{i g}$, which denotes that there exists no shortage of blood product $i$ with blood group $g$, and all the values of row $g$ in the matrix $U V \_$now $_{:,, i}$ should be zero. Similarly, we can judge the value of $y_{g k i}^{*}$ in Step 5.3.2 to simplify the matrix $U V \_$now further.

(4) Compute the remaining optimal substitution amounts based on greedy criterion.

Let $i=1$.

Step 6.2: Obtain a vector $w n$ by sorting the non-zero values of matrix $U V \_n o w_{:,, i}$ in ascending order. Let row and col be the vector of row numbers and the vector of column numbers of each non-zero element in vector $w n$, respectively. Let $j=1: \operatorname{length}(w n)$.

Step 6.2.1: If $y m_{i}>0$, then let $k=$ row $_{j}, g=\operatorname{col}_{j}$, and $y_{k g i}^{*}=\min \left(y m_{i}, s a_{i k}, z a_{i g}\right)$; otherwise, go to Step 6.2.4.

Step 6.2.2: If $y_{k g i}^{*}==s a_{i k}$, then $U V \_n o w_{k,, i}=0$; If $y_{k g i}^{*}==z a_{i g}, \quad$ then $\quad U V_{\_} n o w_{:, g, i}=0 ; \quad$ otherwise, 
$U V \_$now $_{k, g, i}=0$.

Step 6.2.3: Let $s a_{i k}=s a_{i k}-y_{k g i}^{*}, \quad z a_{i g}=z a_{i g}-y_{k g i}^{*}$, $x_{k i}^{*}=x_{k i}^{*}+y_{k g i}^{*}$, and $y m_{i}=y m_{i}-y_{k g i}^{*}$.

Step 6.2.4: Let $j=j+1$ and repeat Steps 6.2.1 to 6.2.3 until $j==$ length $(w n)$.

Step 6.3: Let $i=i+1$ and repeat Step 6.2 until $i==|P|$.

(5) Allocating the substitution amounts and shortages of each blood product

Step 7: The optimal amount of shortage $z_{k p}^{*}$ is equal to $z a_{k p}^{*}$. The substitution amount $y_{i k p, j}$ and the shortage $z_{k p, j}$ of each blood product can be allocated respectively to each blood bank according to constraints 4 and 7 . Calculate the allocation amount of each blood product with each blood group $x_{k p, j}$ according to constraint 2 and the objective function value $F^{*}$.

In the above steps of the proposed heuristic method, we introduced a matrix $U V \_$now to represent the selection process of substitutions, the final value of the matrix can be used to validate the correctness of the substitution process. For example, for product $i$, if $U V \_n o w_{g, j, i}>0$ in the final stage, it denotes that product $i$ with blood group $g$ still has surplus to substitute group $j$, so we check the allocation solution to verify whether the substitution process is completed.

\section{Simulation Experiments}

This study took the emergency blood supply scenario after the Wenchuan Earthquake on 12 May 2008 as an example. The blood products gathered urgently at the Sichuan Blood Center had to be allocated to four blood banks in the affected area: Chengdu (CD), Deyang (DY), Mianyang (MY), and Guangyuan (GY).

Referring to Ma et al. (2015), we estimated the total emergency blood demand of the affected area after the earthquake and then apportioned it among the four blood banks in proportion to their covered population and blood groups. The proportions of blood groups $\mathrm{O}, \mathrm{A}, \mathrm{B}$, and $\mathrm{AB}$ were approximately $36 \%, 32 \%, 24 \%$, and $8 \%$, respectively, while the proportions of blood groups $R h+$ and $R h$ - were approximately $99.65 \%$ and $0.35 \%$, respectively. The allocation of RBCs is shown in Table 3; the remaining lifetime of these blood products was assumed to be at least more than 20 days. The demand for red blood cells at each blood bank in the affected area in the 2 weeks after the Wenchuan Earthquake is listed in Table 4.
Table 3 Red blood cells with each blood group to be allocated at the Chengdu Blood Center after the Wenchuan Earthquake (U)

\begin{tabular}{llllllll}
\hline $\mathrm{AB}+$ & $\mathrm{AB}-$ & $\mathrm{B}+$ & $\mathrm{B}-$ & $\mathrm{A}+$ & $\mathrm{A}-$ & $\mathrm{O}+$ & $\mathrm{O}-$ \\
\hline 1015 & 2 & 4836 & 10 & 4215 & 30 & 7692 & 30 \\
\hline
\end{tabular}

$1 \mathrm{U}$ denotes $200 \mathrm{ml}$ in China

Table 4 Red blood cell demand from each blood bank in the Wenchuan Earthquake affected area (U)

\begin{tabular}{lrlrrrrrr}
\hline Blood & \multicolumn{7}{l}{ Blood Groups } \\
\cline { 2 - 9 } Banks $^{\mathrm{a}}$ & $\mathrm{AB}+$ & $\mathrm{AB}-$ & $\mathrm{B}+$ & $\mathrm{B}-$ & $\mathrm{A}+$ & $\mathrm{A}-$ & $\mathrm{O}+$ & $\mathrm{O}-$ \\
\hline $\mathrm{CD}$ & 1057 & 4 & 3172 & 11 & 4230 & 15 & 4758 & 17 \\
$\mathrm{DY}$ & 96 & 0 & 287 & 1 & 383 & 1 & 431 & 2 \\
MY & 112 & 0 & 335 & 1 & 447 & 2 & 503 & 2 \\
GY & 113 & 0 & 339 & 1 & 451 & 2 & 508 & 2 \\
\hline
\end{tabular}

${ }^{\mathrm{a}} C D$ Chengdu, $D Y$ Deyang, $M Y$ Mianyang, $G Y$ Guangyuan

\subsection{Computational Results of Allocation}

To get the solution with the least shortage, the per-unit penalty on blood shortage $\rho$ should be greater than the maximum priority weight of blood substitution. Let $\rho$ be 10,000 and we set priority weights of $\mathrm{ABO} / R h(\mathrm{D})-\mathrm{com}$ patible blood substitution $w_{i k}$ according to the values listed in Table 1. All priority weights follow the preference order.

The proposed greedy heuristic algorithm was implemented by the Matlab software on a PC platform with an Intel i5 CPU, 8 GB memory, and Windows XP operating system. Table 5 shows the optimal emergency blood allocation scheme when the maximum $\mathrm{ABO} / R h(\mathrm{D})$-compatible substitution rate $\delta$ equals to $5 \%$.

In the column of substitution amounts of Table 5, " $\mathrm{B}+\rightarrow \mathrm{AB}+278$ " denotes that 278 units of $\mathrm{AB}+$ product are substituted with $\mathrm{B}+$ product, while in the column of shortages, "AB-2" denotes the shortage of $\mathrm{AB}-$ product is 2 units.

The results show that when $\delta=5 \%$, there existed ABO/ $R h(\mathrm{D})$-compatible substitutions among different blood groups of each blood product at each blood bank. Moreover, the substitution scheme followed the order of $\mathrm{ABO} /$ $R h(\mathrm{D})$-compatible blood substitution, as shown in Table 1. In Table 5, the substitutions of each blood group among all blood banks are allocated according to their demand proportions, as well as the homotype allocations and shortages of each blood group at each blood banks are all generated under this principle.

The other blood products that are mainly used in disaster relief are whole blood and plasma. As shown in Tables 6 
Table 5 Optimal emergency blood allocation scheme for the studied case after the Wenchuan Earthquake $(\delta=5 \%)$

\begin{tabular}{|c|c|c|c|c|c|c|c|c|c|c|}
\hline \multirow[t]{2}{*}{ Blood Banks $^{\mathrm{a}}$} & \multicolumn{8}{|c|}{ Homotype allocations (U) } & \multirow[t]{2}{*}{ Substitutions (U) } & \multirow[t]{2}{*}{ Shortages (U) } \\
\hline & $\mathrm{AB}+$ & $\mathrm{AB}-$ & $\mathrm{B}+$ & $\mathrm{B}-$ & $\mathrm{A}+$ & $\mathrm{A}-$ & $\mathrm{O}+$ & $\mathrm{O}-$ & & \\
\hline $\mathrm{CD}$ & 779 & 2 & 3450 & 8 & 3235 & 15 & 5142 & 17 & $\begin{array}{l}\mathrm{B}+\rightarrow \mathrm{AB}+278 \\
\mathrm{O}+\rightarrow \mathrm{A}+384\end{array}$ & $\begin{array}{l}\mathrm{AB}-2 \\
\mathrm{~B}-3 \\
\mathrm{~A}+611\end{array}$ \\
\hline DY & 71 & 0 & 312 & 1 & 293 & 1 & 466 & 2 & $\mathrm{~B}+\rightarrow \mathrm{AB}+25 ; \mathrm{O}+\rightarrow \mathrm{A}+35$ & $A+55$ \\
\hline MY & 82 & 0 & 365 & 1 & 341 & 2 & 544 & 2 & $\mathrm{~B}+\rightarrow \mathrm{AB}+30 ; \mathrm{O}+\rightarrow \mathrm{A}+41$ & $A+65$ \\
\hline GY & 83 & 0 & 369 & 0 & 346 & 2 & 548 & 2 & $\mathrm{~B}+\rightarrow \mathrm{AB}+30 ; \mathrm{O}+\rightarrow \mathrm{A}+40$ & $\begin{array}{l}A+65 \\
B-1\end{array}$ \\
\hline
\end{tabular}

${ }^{a} C D$ Chengdu, $D Y$ Deyang, $M Y$ Mianyang, $G Y$ Guangyuan

Table 6 Possible $\mathrm{ABO} / R h(\mathrm{D})$-compatible substitutions for whole blood. Source Oneblood (2018)

\begin{tabular}{|c|c|c|c|c|c|c|c|c|}
\hline \multirow[t]{2}{*}{ Donor } & \multicolumn{8}{|c|}{ Patient } \\
\hline & $\mathrm{AB}+$ & $\mathrm{AB}-$ & $\mathrm{B}+$ & B- & $\mathrm{A}+$ & A- & $\mathrm{O}+$ & $\mathrm{O}-$ \\
\hline $\mathrm{AB}+$ & 1 & $\infty$ & $\infty$ & $\infty$ & $\infty$ & $\infty$ & $\infty$ & $\infty$ \\
\hline $\mathrm{AB}-$ & 2 & 1 & $\infty$ & $\infty$ & $\infty$ & $\infty$ & $\infty$ & $\infty$ \\
\hline B+ & $\infty$ & $\infty$ & 1 & $\infty$ & $\infty$ & $\infty$ & $\infty$ & $\infty$ \\
\hline B- & $\infty$ & $\infty$ & 2 & 1 & $\infty$ & $\infty$ & $\infty$ & $\infty$ \\
\hline $\mathrm{A}+$ & $\infty$ & $\infty$ & $\infty$ & $\infty$ & 1 & $\infty$ & $\infty$ & $\infty$ \\
\hline A- & $\infty$ & $\infty$ & $\infty$ & $\infty$ & 2 & 1 & $\infty$ & $\infty$ \\
\hline $\mathrm{O}+$ & $\infty$ & $\infty$ & $\infty$ & $\infty$ & $\infty$ & $\infty$ & 1 & $\infty$ \\
\hline $\mathrm{O}-$ & $\infty$ & $\infty$ & $\infty$ & $\infty$ & $\infty$ & $\infty$ & 2 & 1 \\
\hline
\end{tabular}

and 7 (Oneblood 2018), the substitution relations of these two products are quite different from the possible compatible substitutions for red blood cell.

With regard to the $\mathrm{ABO} / R h(\mathrm{D})$-compatible substitutions for whole blood, Tables 3 and 4 were used as the data of the supply and demand of whole blood for the experiment. As all $R h(\mathrm{D})$ - products of whole blood have no possible substitution, ABO type products only are substituted by $R h(\mathrm{D})$ - products with same $\mathrm{ABO}$ type, the substitution relations of whole blood are remarkably less than RBCs. According to the testing result, the total shortage increases to 1655 units, and the total substitutions are only 10 units.

With regard to the $\mathrm{ABO} / R h(\mathrm{D})$-compatible substitutions for plasma, Tables 3 and 4 were used as the data of the supply and demand of plasma for a new experiment. According to this testing result, the total shortage increases to 1651 units, and the total substitutions are also only 10 units. The substitutions of plasma are quite different from the compatible substitutions for red blood cells, blood group $\mathrm{O}+/ \mathrm{O}-$ can be substituted by all other seven blood groups, and $\mathrm{AB}+/ \mathrm{AB}-$ can substitute all other blood groups. However, there are more surplus $\mathrm{O}+$ products in
Table 7 Possible $\mathrm{ABO} / R h(\mathrm{D})$-compatible substitutions for plasma. Source Oneblood (2018)

\begin{tabular}{|c|c|c|c|c|c|c|c|c|}
\hline \multirow[t]{2}{*}{ Donor } & \multicolumn{8}{|c|}{ Patient } \\
\hline & $\mathrm{AB}+$ & $\mathrm{AB}-$ & $\mathrm{B}+$ & B- & $\mathrm{A}+$ & A- & $\mathrm{O}+$ & $\mathrm{O}-$ \\
\hline $\mathrm{AB}+$ & 1 & 2 & 2 & 2 & 2 & 2 & 2 & 2 \\
\hline $\mathrm{AB}-$ & 2 & 1 & 2 & 2 & 2 & 2 & 2 & 2 \\
\hline $\mathrm{B}+$ & $\infty$ & $\infty$ & 1 & $\infty$ & $\infty$ & $\infty$ & 2 & 2 \\
\hline B- & $\infty$ & $\infty$ & $\infty$ & 1 & $\infty$ & $\infty$ & 2 & 2 \\
\hline $\mathrm{A}+$ & $\infty$ & $\infty$ & $\infty$ & $\infty$ & 1 & 2 & 2 & 2 \\
\hline A- & $\infty$ & $\infty$ & $\infty$ & $\infty$ & 2 & 1 & 2 & 2 \\
\hline $\mathrm{O}+$ & $\infty$ & $\infty$ & $\infty$ & $\infty$ & $\infty$ & $\infty$ & 1 & 2 \\
\hline $\mathrm{O}-$ & $\infty$ & $\infty$ & $\infty$ & $\infty$ & $\infty$ & 2 & 2 & 1 \\
\hline
\end{tabular}

the experiment data, so there are very few substitutions in the allocation solution.

In the above experiments for whole blood and plasma, if we had collected these blood products with different groups at the same proportion as red cells, there would be severe shortages in the allocation solution. Different blood products have different substitution rules, so it is suggested to collect more of these blood products with the blood groups that can substitute other blood groups to cause less shortages.

Through the above experiments, the feasibility of the heuristic algorithm we proposed is confirmed. By checking the relation between the values of matrix $U V \_$now and the allocation solution, the correctness of the algorithm is validated. The computation time of the heuristic method for these scenarios is within $2 \mathrm{~s}$. During the above experiments, we also found that the allocation solutions are not unique as the possible substitution weights are the same values when substitutions happen. 
Fig. 5 Total substitution amounts and shortages with the change in the maximum compatible substitution rate

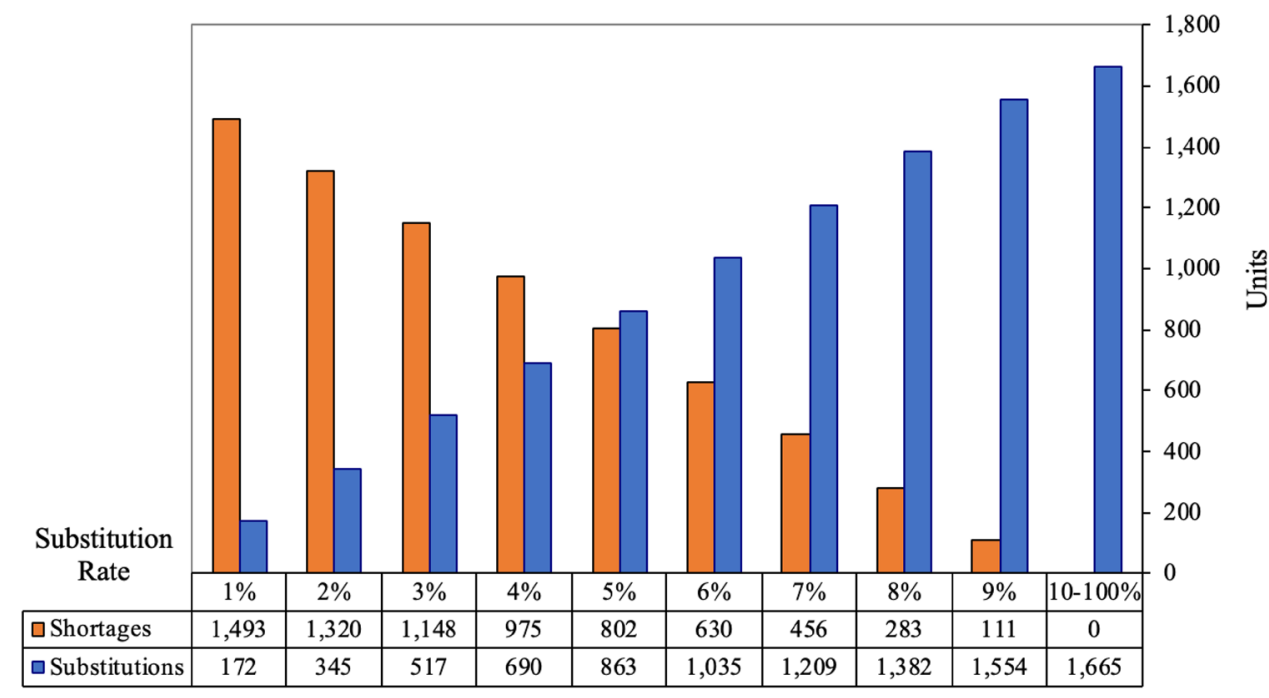

\subsection{Sensitivity Analysis of Substitution Rate}

To further investigate the effect of an $\mathrm{ABO} / R h(\mathrm{D})$-compatible blood substitution policy, we performed a sensitivity analysis with change in the maximum $\mathrm{ABO} / R h(\mathrm{D})$ compatible substitution rate $\delta$ and obtained the corresponding total substitution amounts and shortages, as shown in Fig. 5.

When $\mathrm{ABO} / R h(\mathrm{D})$-compatible blood substitution is not allowed, the total shortage of blood products within each blood group at the four blood banks reaches 1665 units. As the maximum $\mathrm{ABO} / R h(\mathrm{D})$-compatible substitution rate $\delta$ increases, the total shortage decreases while the total substitution amount increases. When $\delta \geq 10 \%$, both the total substitution amount and the total shortage remain constant due to the maximum possibility of $\mathrm{ABO} / R h(\mathrm{D})$-compatible blood substitution.

The result shows that an $\mathrm{ABO} / R h(\mathrm{D})$-compatible substitution policy can significantly reduce the unmet rate of emergency blood demand and enhance the emergency blood supply level in disaster relief operations. With the increase of the maximum $\mathrm{ABO} / R h(\mathrm{D})$-compatible substitution rate among different blood groups, the total shortage of blood products decreases while the total substitution amount increases. Setting an appropriate maximum $\mathrm{ABO} /$ $R h(\mathrm{D})$-compatible substitution rate, however, is a thorny problem for the decision maker. We should get a balance between less unmet demand and fewer allotypic transfusions since allotypic transfusions with blood substitutions are riskier than homotype transfusions.

\subsection{Priorities of $\mathrm{ABO} / \mathrm{Rh}(\mathrm{D})$-Compatible Substitution}

In practice, doctors may have their own preferences for substitution transfusion according to their clinical
Table 8 Assumed preference order of possible $\mathrm{ABO} / R h(\mathrm{D})$-compatible substitutions for red blood cells. Source Lang (2010)

\begin{tabular}{lllllllll}
\hline Donor & \multicolumn{7}{l}{ Patient's preference order } \\
\cline { 2 - 8 } & $\mathrm{AB}+$ & $\mathrm{AB}-$ & $\mathrm{B}+$ & $\mathrm{B}-$ & $\mathrm{A}+$ & $\mathrm{A}-$ & $\mathrm{O}+$ & $\mathrm{O}-$ \\
\hline $\mathrm{AB}+$ & 1 & $\infty$ & $\infty$ & $\infty$ & $\infty$ & $\infty$ & $\infty$ & $\infty$ \\
$\mathrm{AB}-$ & 2 & 1 & $\infty$ & $\infty$ & $\infty$ & $\infty$ & $\infty$ & $\infty$ \\
$\mathrm{B}+$ & 3 & $\infty$ & 1 & $\infty$ & $\infty$ & $\infty$ & $\infty$ & $\infty$ \\
$\mathrm{B}-$ & 4 & 2 & 2 & 1 & $\infty$ & $\infty$ & $\infty$ & $\infty$ \\
$\mathrm{A}+$ & 5 & $\infty$ & $\infty$ & $\infty$ & 1 & $\infty$ & $\infty$ & $\infty$ \\
$\mathrm{A}-$ & 6 & 3 & $\infty$ & $\infty$ & 2 & 1 & $\infty$ & $\infty$ \\
$\mathrm{O}+$ & 7 & $\infty$ & 3 & $\infty$ & 3 & $\infty$ & 1 & $\infty$ \\
$\mathrm{O}-$ & 8 & 4 & 4 & 2 & 4 & 2 & 2 & 1 \\
\hline
\end{tabular}

experience. For decision makers of emergency blood allocation, it is important to understand the impact of priorities of $\mathrm{ABO} / R h(\mathrm{D})$-compatible substitution on allocation solution.

In Table 8 we list a meticulous blood type preference order for substitution for red blood cells that was assumed by Lang (2010): Blood demand should first be satisfied by the exact $\mathrm{ABO} / R h(\mathrm{D})$ match-lower substitution weight among blood groups stands for higher priority, so "1" stands for the highest priority, " 8 " stands for the lowest priority, and " $\infty$ " means not feasible. If the exact match is not available, an $\mathrm{ABO} / R h(\mathrm{D})$-compatible match could be sought according to the substitution priority.

We used the priority weight for $\mathrm{ABO} / R h(\mathrm{D})$-compatible substitutions in Table 8 and the supply and demand data from Sect. 5.1 for a new experiment and the testing results are shown in Table 9. The total shortage is 802 units, and the total substitutions are 863 units. These amounts for shortage and substitutions are the same as in Table 5, but substitutions among blood groups are different. 
Table 9 Optimal emergency blood allocation scheme of red blood cells under preference order for substitution $(\delta=5 \%)$

\begin{tabular}{|c|c|c|c|c|c|c|c|c|c|c|}
\hline \multirow[t]{2}{*}{ Blood Banks $^{\mathrm{a}}$} & \multicolumn{8}{|c|}{ Homotype allocations (U) } & \multirow[t]{2}{*}{ Substitutions (U) } & \multirow[t]{2}{*}{ Shortages (U) } \\
\hline & $\mathrm{AB}+$ & $\mathrm{AB}-$ & $\mathrm{B}+$ & $\mathrm{B}-$ & $\mathrm{A}+$ & $\mathrm{A}-$ & $\mathrm{O}+$ & $\mathrm{O}-$ & & \\
\hline $\mathrm{CD}$ & 779 & 2 & 3450 & 8 & 3235 & 23 & 5131 & 20 & $\begin{array}{l}\mathrm{B}+\rightarrow \mathrm{AB}+278 \\
\mathrm{~A}-\rightarrow \mathrm{A}+8 \\
\mathrm{O}-\rightarrow \mathrm{B}-3 \\
\mathrm{O}+\rightarrow \mathrm{A}+373\end{array}$ & $\begin{array}{l}\mathrm{AB}-2 \\
\mathrm{~A}+614\end{array}$ \\
\hline DY & 71 & 0 & 312 & 1 & 292 & 2 & 465 & 2 & $\begin{array}{l}\mathrm{B}+\rightarrow \mathrm{AB}+25 \\
\mathrm{~A}-\rightarrow \mathrm{A}+1 \\
\mathrm{O}+\rightarrow \mathrm{A}+34\end{array}$ & $A+55$ \\
\hline MY & 82 & 0 & 365 & 1 & 342 & 3 & 542 & 2 & $\begin{array}{l}\mathrm{B}+\rightarrow \mathrm{AB}+30 \\
\mathrm{~A}-\rightarrow \mathrm{A}+1 \\
\mathrm{O}+\rightarrow \mathrm{A}+39\end{array}$ & $A+65$ \\
\hline GY & 83 & 0 & 369 & 0 & 346 & 2 & 548 & 3 & $\begin{array}{l}\mathrm{B}+\rightarrow \mathrm{AB}+30 \\
\mathrm{O}-\rightarrow \mathrm{B}-1 \\
\mathrm{O}+\rightarrow \mathrm{A}+40\end{array}$ & $A+65$ \\
\hline
\end{tabular}

${ }^{a} C D$ Chengdu, $D Y$ Deyang, $M Y$ Mianyang, $G Y$ Guangyuan

For example, if $\mathrm{RBCs}$ with the $\mathrm{AB}-$ group are in shortage but $\mathrm{RBCs}$ with the $\mathrm{A}-$ group and $\mathrm{O}-$ group are both in surplus, then the $\mathrm{A}-$ group will be selected as the substitute because of its higher priority. Comparing Table 9 with Table 5, as $\mathrm{A}+$ products are in shortage, $\mathrm{O}+$ products are only selected to substitute $\mathrm{A}+$ products in Table 5 (384 units) for blood bank CD; however, under the preference order for substitution, $\mathrm{O}+$ products are less often selected to substitute A+ products in Table 9 (373 units). In the allocation solution for $\mathrm{CD}$ in Table 9, at higher priority (lower priority weight), 8 units of $\mathrm{A}-$ products are selected to substitute $\mathrm{A}+$ products, and 3 units $\mathrm{O}-$ products are selected to substitute $\mathrm{B}-$ products. The priority weight of $\mathrm{O}+$ for $\mathrm{A}+$ is 3 , but the priority weight of $\mathrm{A}-$ for $\mathrm{A}+$ is 2 and $\mathrm{O}-$ for $\mathrm{B}-$ is 2 , so these higher priority substitutions are considered first before lower priority substitutions.

In the solution for other blood banks, the priority substitutions also happen, so the allocation has the best value of the objective function. The result shows that considering the preference order of substitution will remarkably enhance the practical application of the proposed model under the scenario in which doctors can set the preference for substitution transfusion according to their clinical experience.

\section{Discussions}

The findings of this study provide the following research implications:
- This study contributes to the understanding of emergency blood allocation problem in disaster relief operations. Particularly, we consider possible ABO/ $R h(\mathrm{D})$-compatible substitutions among different blood groups. The priority weights of $\mathrm{ABO} / R h(\mathrm{D})$-compatible blood substitution were used to represent possible substitution priorities among different blood groups. Then, a mixed integer programming model was developed for the emergency blood allocation problem in disaster relief operations with consideration of complex $\mathrm{ABO} / R h(\mathrm{D})$ compatibility. To the best of our knowledge, this is the first study to investigate the emergency blood allocation problem in disaster relief operations, especially considering $\mathrm{ABO} / R h(\mathrm{D})$ compatibility.

- In view of the complexity of $\mathrm{ABO} / R h(\mathrm{D})$ compatibility and the high-dimensional optimization task, this study proposed a greedy heuristic algorithm to solve the developed model. The application of greedy rules improves the optimization capability efficiently. Except for its advantages in real-time computing and adaptability to different scales, the heuristic algorithm used in the study can also deal with any type of objective function model as well as output the optimal solution of the model just by adding a few steps to the procedure.

- The proposed model is able to adapt to a variety of substitution preference order, which will remarkably enhance the practical application of this research. If we set the order values of possible compatible substitutions for other blood groups the same, the allocation solution is not unique. The experiments in Sect. 5.1 also can verify this. 
- This study quantifies the effect of an $\mathrm{ABO} / R h(\mathrm{D})$ compatible substitution policy on emergency blood allocation. The result shows in Sect. 5.2 that the unmet rate of emergency blood demand can be decreased significantly by using an $\mathrm{ABO} / R h(\mathrm{D})$-compatible substitution policy, especially with a high maximum compatible substitution rate.

This study not only offered a general decision-making framework for emergency blood allocation in disaster relief operations, but also revealed the following managerial insights:

- Based on the simulation experiments of Sect. 5, we can conclude that allowing $\mathrm{ABO} / R h(\mathrm{D})$-compatible blood substitution in emergency blood allocation can decrease the shortages of blood products significantly and keep the shortage rate within an acceptable level. Accordingly, the satisfaction degree of emergency blood demand can be improved remarkably.

- Blood product collection scheme should be adjusted based on its possible $\mathrm{ABO} / R h(\mathrm{D})$-compatible substitution in emergency management. The more a blood group can substitute other blood groups, the larger amount the products with this kind of blood group should be collected. We should recognize that the possible $\mathrm{ABO} / R h(\mathrm{D})$-compatible substitution relations among the different blood products are not the same. The tests in Sect. 5.1 show that, if there is no particular consideration of different possible compatible substitutions during different blood product collection, there may be severe shortages in the allocation solution.

- The higher the substitution rate, the less the shortage rate. As the result in Sect. 5.2 shows, theoretically we can narrow the gap between the demand and supply of blood products with each blood group by increasing the maximum $\mathrm{ABO} / R h(\mathrm{D})$-compatible substitution rate. But in practice, allotypic transfusion only accounts for approximately $5 \%$ of routine clinical medical treatments (BSMS 2003). Setting an upper limit on the substitution rate can help avoid potential domino effect caused by $\mathrm{ABO} / R h(\mathrm{D})$-compatible blood substitution, that is, when one group of blood product is used to substitute other groups in the current period, this group of blood product may be in shortage and must be substituted by other groups in the subsequent periods.

- In addition, preference order of possible $\mathrm{ABO} / R h(\mathrm{D})$ compatible substitutions influences the allocation solution. As the experiments in Sect. 5.3 show, for the decision makers of emergency blood allocation, setting the substitution order in advance according to the preference of local doctors is important to reaching a suitable allocation solution.

\section{Conclusion}

Motivated by the practice of emergency blood supply in disaster relief operations, in this study we examined a multi-product multi-group emergency blood allocation problem considering $\mathrm{ABO} / R h(\mathrm{D})$-compatible blood substitution. Based on the restriction and priority of possible $\mathrm{ABO} / R h(\mathrm{D})$-compatible blood substitutions, a mixed integer programming model was developed to address the emergency blood allocation problem in disaster relief operations, which was solved by a greedy heuristic algorithm. Finally, a numerical example is presented to verify the model and algorithm and analyze the effect of an $\mathrm{ABO} /$ $R h(\mathrm{D})$-compatible blood substitution policy on emergency blood allocation. The proposed model can help decision makers to design appropriate emergency blood allocation schemes with consideration of $\mathrm{ABO} / R h(\mathrm{D})$-compatible blood substitution, to alleviate the dilemma of blood supply in a disaster affected area.

$\mathrm{ABO} / R h(\mathrm{D})$-compatible blood substitution is undoubtedly an effective way to decrease blood shortage in emergency blood allocation. We should collect blood products with different blood groups based on their possible $\mathrm{ABO} / R h(\mathrm{D})$-compatible substitution in emergency. Collecting more blood products with the blood groups that can substitute other blood groups will reduce shortages. It is also suggested to set an upper limit to the $\mathrm{ABO} / R h(\mathrm{D})$ compatible substitution rate among different blood groups.

Although this study contributes to the exploration of the multi-group emergency blood allocation problem in disaster relief operations and has important implications for practice, some opportunities exist for further research, which may include: (1) develop a multi-period decisionmaking framework for emergency blood allocation considering the uncertainties of supply and demand in disaster relief operations; (2) evaluate how to set an appropriate $\mathrm{ABO} / R h(\mathrm{D})$-compatible substitution rate among blood groups at different disaster relief stages to reduce the unmet blood demand and prevent the domino effect caused by $\mathrm{ABO} / R h(\mathrm{D})$-compatible blood substitution; (3) consider the age of blood products; and (4) extend our model to cover other relevant decisions in addition to allocation decision, such as location-allocation model, inventory-allocation decision model, among others.

Acknowledgements The authors are grateful to the editors and the reviewers for their constructive comments and invaluable contributions to enhance the presentation of this paper. This work was supported by the National Natural Science Foundation of China (Nos. 71502146, 71672154, and 90924012) and Humanities and Social Sciences Foundation of the Ministry of Education of China (No. 16YJA630038). 
Open Access This article is distributed under the terms of the Creative Commons Attribution 4.0 International License (http://crea tivecommons.org/licenses/by/4.0/), which permits unrestricted use, distribution, and reproduction in any medium, provided you give appropriate credit to the original author(s) and the source, provide a link to the Creative Commons license, and indicate if changes were made.

\section{References}

Abdulwahab, U., and M.I.M. Wahab. 2014. Approximate dynamic programming modeling for a typical blood platelet bank. Computers \& Industrial Engineering 78: 259-270.

Abolghasemi, H., M.H. Radfar, M. Tabatabaee, N.S. HosseiniDivkolayee, and F.M. Burkle. 2008. Revisiting blood transfusion preparedness: Experience from the Bam Earthquake response. Prehospital and Disaster Medicine 23(5): 391-394.

Atkinson, M.P., M.J. Fontaine, L.T. Goodnough, and L.M. Wein. 2012. A novel allocation strategy for blood transfusions: Investigating the tradeoff between the age and availability of transfused blood. Transfusion 52(1): 108-117.

Bakker, M., J. Riezebos, and R.H. Teunter. 2012. Review of inventory systems with deterioration since 2001. European Journal of Operational Research 221(2): 275-284.

Beliën, J., and H. Forcé. 2012. Supply chain management of blood products: A literature review. European Journal of Operational Research 217(1): 1-16.

BSMS (Blood Stocks Management Scheme). 2003. Inventory practice survey. http://www.bloodstocks.co.uk/pdf/annualreport2003-4. pdf. Accessed 20 May 2017.

Dillon, M., F. Oliveira, and B. Abbasi. 2017. A two-stage stochastic programming model for inventory management in the blood supply chain. International Journal of Production Economics 187: 27-41.

Duan, Q.L., and T.W. Liao. 2014. Optimization of blood supply chain with shortened shelf lives and ABO compatibility. International Journal of Production Economics 153: 113-129.

Ensafian, H., S. Yaghoubi, and M.M. Yazdi. 2017. Raising quality and safety of platelet transfusion services in a patient-based integrated supply chain under uncertainty. Computers \& Chemical Engineering 106: 355-372.

Ensafian, H., and S. Yaghoubi. 2017. Robust optimization model for integrated procurement, production and distribution in platelet supply chain. Transportation Research Part E: Logistics and Transportation Review 103: 32-55.

Fahimnia, B., A. Jabbarzadeh, A. Ghavamifar, and M. Bell. 2017. Supply chain design for efficient and effective blood supply in disasters. International Journal of Production Economics 183: 700-709.

Fazli-Khalaf, M., S. Khalilpourazari, and M. Mohammadi. 2017. Mixed robust possibilistic flexible chance constraint optimization model for emergency blood supply chain network design. Annals of Operations Research. https://doi.org/10.1007/s10479017-2729-3.

Federgruen, A., G. Prastacos, and P.H. Zipkin. 1986. An allocation and distribution model for perishable products. Operations Research 34(1): 75-82.

Ganesh, K., T.T. Narendran, and S.P. Anbuudayasankar. 2014. Evolving cost-effective routing of vehicles for blood bank logistics. International Journal of Logistics Systems and Management 17(4): 381-415.

Gregor, P.J., R.N. Forthofer, and A.S. Kapadia. 1982. An evaluation of inventory and transportation policies of a regional blood distribution system. European Journal of Operational Research 10(1): 106-113.

Hemmelmayr, V., K.F. Doerner, R.F. Hartl, and M.W. Savelsbergh. 2009. Delivery strategies for blood products supplies. $O R$ Spectrum 31(4): 707-725.

Hess, J.R., and M.J. Thomas. 2003. Blood use in war and disaster: Lessons from the past century. Transfusion 43(11): 1622-1633.

Ibrion, M., M. Mokhtari, and F. Nadim. 2015. Earthquake disaster risk reduction in Iran: Lessons and "lessons learned" from three large earthquake disasters-Tabas 1978, Rudbar 1990, and Bam 2003. International Journal of Disaster Risk Science 6(4): 415-427.

Jabbarzadeh, A., B. Fahimnia, and S. Seuring. 2014. Dynamic supply chain network design for the supply of blood in disasters: A robust model with real world application. Transportation Research Part E: Logistics and Transportation Review 70: 225-244.

Jafarkhan, F., and S. Yaghoubi. 2018. An efficient solution method for the flexible and robust inventory-routing of red blood cells. Computers \& Industrial Engineering. https://doi.org/10.1016/j. cie.2018.01.029.

Karaesmen, I.Z., A. Scheller-Wolf, and B. Deniz. 2011. Managing perishable and aging inventories: Review and future research directions. In Planning production and inventories in the extended enterprise, ed. K.G. Kempf, P. Keskinocak, and R. Uzsoy, 393-436. Boston, MA: Springer.

Khalilpourazari, S., and A.A. Khamseh. 2017. Bi-objective emergency blood supply chain network design in earthquake considering earthquake magnitude: A comprehensive study with real world application. Annals of Operations Research. https://doi. org/10.1007/s10479-017-2588-y.

Lang, J.C. 2010. Blood bank inventory control with transshipments and substitutions. In Production and inventory management with substitutions, ed. J.C. Lang, 205-226. Berlin: Springer.

Liu, J., Y. Huang, J.X. Wang, X. Bi, J. Li, Y. Lu, X. Wen, F. Yao, et al. 2010. Impact of the May 12, 2008, earthquake on blood donations across five Chinese blood centers. Transfusion 50(9): 1972-1979.

Ma, Z.J., Y. Dai, and K.M. Wang. 2015. Theory and methods for emergency blood supply in unconventional emergencies. Beijing: Science Press (in Chinese).

Mujeeb, S.A., and S.H. Jaffery. 2007. Emergency blood transfusion services after the 2005 earthquake in Pakistan. Emergency Medicine Journal 24(1): 22-24.

Nahmias, S. 1982. Perishable inventory theory: A review. Operations Research 30(4): 680-708.

Najafi, M., A. Ahmadi, and H. Zolfagharinia. 2017. Blood inventory management in hospitals: Considering supply and demand uncertainty and blood transshipment possibility. Operations Research for Health Care 15: 43-56.

NHS (National Health Service). 2012. Blood group O RhD negative red blood cells information for clinical and laboratory staff. http://hospital.blood.co.uk/media/2336/f84024fc-89ae-45359d21-16a24f08d336.pdf. Accessed 20 May 2017.

Olusanya, M.O., and A.O. Adewumi. 2014. Using metaheuristic techniques to optimize the blood assignment problem. In Proceedings of 2014 IEEE International Advance Computing Conference (IACC 2014), 21-22 February 2014, Gurgaon, India, 1331-1336.

Oneblood. 2018. About blood types. https://www.oneblood.org/ about-donating/blood-donor-basics/what-is-blood/about-bloodtypes.stml. Accessed 16 Apr 2018.

Osorio, A.F., S.C. Brailsford, and H.K. Smith. 2015. A structured review of quantitative models in the blood supply chain: A taxonomic framework for decision-making. International Journal of Production Research 53(24): 7191-7212. 
Osorio, A.F., S.C. Brailsford, and H.K. Smith. 2018. Whole blood or apheresis donations? A multi-objective stochastic optimization approach. European Journal of Operational Research 266(1): 193-204.

Pierskalla, W.P. 2005. Supply chain management of blood banks. In Operations research and health care, ed. M.L. Brandeau, F. Sainfort, and W.P. Pierskalla, 103-145. New York: Springer.

Prastacos, G.P. 1981. Allocation of a perishable product inventory. Operations Research 29(1): 95-107.

Prastacos, G.P. 1984. Blood inventory management: An overview of theory and practice. Management Science 30(7): 777-800.

Sahin, G., H. Sural, and S. Meral. 2007. Locational analysis for regionalization of Turkish Red Crescent blood services. Computers and Operations Research 34: 692-704.

Samani, M.R.G., S.A. Torabi, and S.M. Hosseini-Motlagh. 2018. Integrated blood supply chain planning for disaster relief. International Journal of Disaster Risk Reduction 27: 168-188.
Sapountzis, C. 1984. Allocating blood to hospitals from a central blood bank. European Journal of Operational Research 16: $157-162$.

Sharma, B., M. Ramkumar, N. Subramanian, and B. Malhotra. 2017. Dynamic temporary blood facility location-allocation during and post-disaster periods. Annals of Operations Research. https://doi. org/10.1007/s10479-017-2680-3.

Wang, K.M., and Z.J. Ma. 2015. Age-based policy for blood transshipment during blood shortage. Transportation Research Part E: Logistics and Transportation Review 80: 166-183.

Zahiri, B., and M.S. Pishvaee. 2017. Blood supply chain network design considering blood group compatibility under uncertainty. International Journal of Production Research 55(7): 2013-2033. 